\title{
Interactive Multimedia Games to Enhance the Emotional Intelligence of Deaf and Hard of Hearing Adolescents
}

\section{Nuttapun Nakpong}

Ph.D. candidate, Division of Learning Innovation and Technology, Faculty of Industrial Education and Technology, King Mongkut's University of Technology Thonburi, Bangkok, Thailand, nuttapun.n@mail.kmutt.ac.th

\section{Sumalee Chanchalor}

Assoc. Prof., Division of Learning Innovation and Technology, Faculty of Industrial Education and Technology, King Mongkut's University of Technology Thonburi, Bangkok, Thailand, sumalee.cha@kmutt.ac.th

The purpose of this study was to design and test interactive multimedia games to enhance the emotional intelligence (EI) of deaf and hard of hearing (DHH) learners age 13 to 15 in Thailand. The main content of each of the six games focused on improving EI. The interactive multimedia game was tested with $10 \mathrm{DHH}$ learners in a school for the deaf in the eastern part of Thailand over a 12-week period. The Thai Emotional Intelligence Screening Test (TEIST) served as a pre- and post-test. The results were analyzed using the Wilcoxon Signed-Rank test. The results of the study showed a significant improvement for emotional-self-control, empathy, problem-solving, self-regard, life-satisfaction, and peace in all participants. Overall results showed that the interactive multimedia games can have beneficial effects on the EI of DHH learners.

Keywords: emotional intelligence, deaf and hard-of-hearing, game design, educational technology, Thai Emotional Intelligence Screening Test (TEIST)

\section{INTRODUCTION}

Deaf and hard of hearing (DHH) children are more likely than their peers to have low self-esteem, feel more lonely and be more withdraw and less social (Keilmann, Limberger, \& Mann, 2007). Being deaf can result in a reduction of quality of life and of social activities and this reduction can itself result in feelings associated with rejection and withdrawal (Masoume, Mohammad, \& Seyede, 2013). Not surprisingly, DHH learners are often more likely to be victimized by peers than are those who can hear (Tresh, 2014). Being victimized puts DHH individuals at risk for subsequent emotional problems (Perry, Hodges, \& Egan, 2001). Additionally, parents of DHH children are

Citation: Nakpong, N., \& Chanchalor, S. (2019). Interactive Multimedia Games to Enhance the Emotional Intelligence of Deaf and Hard of Hearing Adolescents. International Journal of Instruction, 12(2), 305-320. https://doi.org/10.29333/iji.2019.12220a 
more likely to identify emotional and behavioural problems in these children (Dammeyer, 2010). Rieffe (2012) found that DHH children showed limited ability to be aware of or acknowledge their emotions "which in turn might negatively affect their emotion regulation capacities" (p. 479). They may be less able than their peers to regulate emotions because of a lack of ability to use various strategies such as diverting attention when faced with problems "beyond control" (Rieffe, 2012, p. 489). Additionally, Rieffe found that mothers demonstrated less patience with their DHH children and were "more inclined to direct the children, and give them less scope to explore and learn from their mistakes" (p. 488).

Programs that are focused on emotional intelligence (EI) can help individuals affected by hearing loss (Pourmohamadreza-Tajrishi and Jalilabkenar, 2013). Interventions using computers, ICTs, multimedia and technology may also have a role to play in promoting the EI of DHH children. Such interventions have proven effective for the cognitive domain. For example, Barker (2003) promoted vocabulary acquisition with DHH learners using a computer-based vocabulary tutor in oral-deaf education. Use of computer-based games can also motivate and engage students (Khenissi, Essalmi, Bouzid \& Jemni, 2015; Visutsak, 2016).

Giannakos and Jaccheri (2014) noted that it is difficult to design computer-based learning for DHH learners and that it is necessary to design in relation to their needs. DHH learners need a different style or approach to learning with computers yet their needs have often been overlooked in the design (Ibrahim, Alias \& Nordin, 2016). For example, computer-based educational games tend not to focus on learners with special needs such as DHH learners (Khenissi, Essalmi, Bouzid \& Jemni, 2015). There have been a number of studies that have focused on the use of technology with DHH learners. However, these tend to focus not on EI but on, for example, learning mathematics (e.g., Techaraungrong, Suksakulchai, Kaewprapan \& Murphy, 2017), learning sign language (e.g., Lee et al., 2005) or vocabulary acquisition, literacy training (Holmer, Heimann, \& Rudner, 2017).

\section{OBJECTIVES}

1) Design interactive multimedia games to meet the needs of DHH learners.

2) Assess by pre and post-test the EI of DHH adolescent learners.

\section{LITERATURE REVIEW}

\section{Emotional Intelligence}

Although the construct of EI was first explored in the literature in the 1990s (e.g., Mayer and Salovey, 1995; Salovey and Mayer, 1990), it remains a concept that is relevant in the $21^{\text {st }}$ century. EI is related to cognitive intelligence (Rafaila, 2015) which makes it an important concept in learning because of its predictive ability in relation to academic achievement and success. It is important in a context of learning because of its association with interpersonal relationships and with adjusting to one's environment (Rafaila 2015, p. 164) for mediating relationships and behavior (Billings et al., 2014). It has also been associated with creativity (Hansenne and Legrand, 2012). The concept has 
been conceptualized according to trait EI versus ability EI (Mavroveli et al., 2008). For example, Petrides et al. (2004) identified a correlation between high EI and higher performance in English with low-IQ learners.

\section{DHH Learners and Technology}

There have been various attempts to make use of technology to help DHH learners. Chebka and Essalmi (2015) created an accessible Arabic crossword game to help DHH learners acquire language and vocabulary. The authors identified benefits of the game such as engagement and motivation. Bouzid, Khenissi and Jemni (2015) created a game generator that can be used by teachers without programming skills to create educational computer games for DHH learners. Similar efforts to integrate technology into learning activities have been created for adults. Ghoul and Jemni (2009) in Tunisia created an open source tool for use by DHH learners that uses avatars and sign animation generated from textual descriptions. As with Khenissi et al., (2015) tool, this technology allows instructors without programming skills to create avatars. Passig and Eden (2000) created rotating virtual reality (VR) three-dimensional (3D) objects to help DHH learners develop inductive reasoning skills. The authors concluded that VR 3D spatial rotations significantly improved inductive thinking.

Techaraungrong, Suksakulchai, Kaewprapan and Murphy (2017) designed and tested multimedia for teaching arithmetic to DHH primary school learners in Thailand. The focus in the design was on minimizing cognitive load for the learners through reducing use of text, using non-symbolic objects, and giving users control. Test results revealed higher scores for those learning with multimedia than those who learned with only the teacher. Mathsigner (Nicoletta \& Ronnie, 2007) involves activities based on American Sign Language and uses 3D animation and virtual reality technology for teaching math. Brashear et al. (2006) created an interactive computer game called CopyCat that relies on gesture recognition technology to help DHH learners practice American Sign Language (ASL) in complete sentences and develop their linguistic skills in motivating and engaging ways. The game includes videos that illustrate the correct signs, live video that provides the DHH learner with feedback as well as an animated character that allows the child to communicate with the computer using ASL.

\section{Design Considerations for DHH Learners}

Mascio et al. (2013) outlined the design considerations for DHH learners based on a review of the literature. The design must take into account the special characteristics of these individuals including reading and vocabulary skills that are likely to be lower than their non-hearing impaired peers and "visuo-perceptual skill" that may be equal. Regarding the visual perception of DHH learners, the authors noted regarding game design that tasks should focus their "attention to the centre of the visual field" (p. 227). They explained that DHH learners are more likely to be inattentive and less likely to engage in "cooperative activities" (p. 228). As a result, games should be designed so as to limit choices and distractions and should include feedback. General design considerations specify that games should involve movement with "human-like avatars" on mobile devices with "points and challenges" (p. 231). Techaraungrong et al. (2017) 
presented design considerations for using multimedia to teach arithmetic to DHH learners. The author's design considerations echoed some of those from Mascio et al. (2013) such as the need for segmented content and strategic presentation of material to overcome inattention. The authors also noted the need for a human signer, human-like expressions and user control.

\section{METHOD}

Objective 1: Design interactive multimedia games to meet the needs of DHH learners

The process of developing the multimedia games concentrated on meeting the needs of players and at the same time, developing players' emotional intelligence. After assessing DHH learners' needs and games design theory, the researchers began to design the content of the game.

\section{Participants}

The game was tested with five DHH learners (3 males and 2 females), from 13 to 15 years of age. After creating the storyboard, the principal investigator sent the game content to experts in each field in order to validate it.

\section{Instruments}

The game design relied on three main software programs. Adobe Flash was used to create the core content of the game, drawing, sounds and animation. Adobe Photoshop was used to decorate the images, and to adjust the light and color. Adobe Premiere was used to edit the video recorded by the sign language interpreter to be used in the games. Each section was then integrated in Adobe Flash.

\section{Procedures}

The researcher began by plotting all of the content to meet DHH learners' needs and the scope of EI, followed by assigning the game title, volume, and drawing the event lines with a pencil on the storyboard in each of the six games. The content was determined to be suitable by the experts. The next step was to design an interactive multimedia game to test the game before the trial. It was carried out in six steps as seen in Table 1.

Table 1

Steps for Creation of the Interactive Multimedia Game

\begin{tabular}{cl}
\hline Step & \multicolumn{1}{c}{ Procedures } \\
\hline 1 & Create game content and game design \\
2 & Create the storyboard \\
3 & Verification of content and storyboard by five \\
& experts \\
4 & Create prototype \\
5 & Trialing the prototype \\
6 & Redesigning of the prototype \\
\hline
\end{tabular}

Step 1: Create game content and game design 
The development of the game content, as well as the game design for improving the EI of DHH learners, were derived from three sources: EI, game design technique, and the needs of DHH learners (Figure 1).

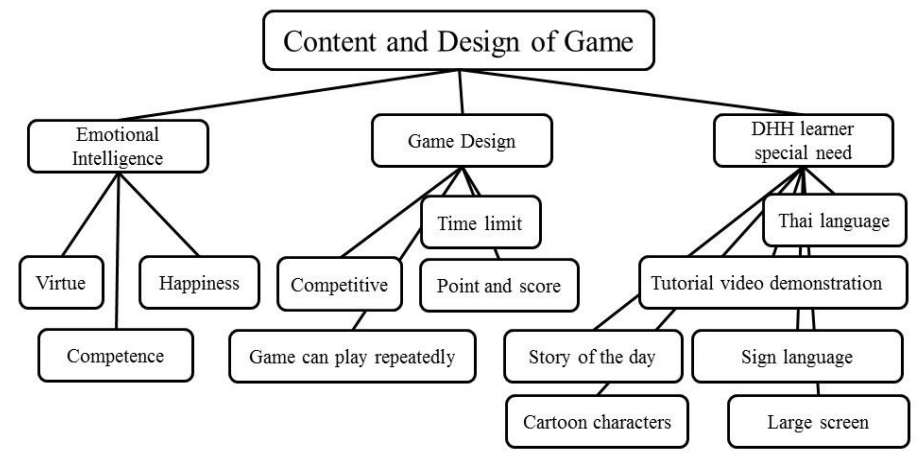

Figure 1

Game Content and Design to Develop EI of DHH Learners

The framework for the EI consisted of three categories as specified by the Thai Department of Mental Health. (2000) virtue, competence, and happiness, as well as the nine sub-categories of emotional self-control, empathy, responsibility, self-motivation, problem-solving, interpersonal relationships, self-regard, life-satisfaction, and peace.

The content of each game focused on different areas of development of EI for DHH learners to reach their full potential; for example, "good driving and kindness" relate to the practice of self-control.

In order to make the multimedia game interesting, Mayer and Moreno (2003) suggested that DHH games should focus on images, signs, and colors because the DHH are visual learners. Thus, extensive and complicated messages should be avoided. Also, some features need to be included such as competition, scoring, a time limit and, the option to play repeatedly.

\section{Step 2: Create the storyboard}

After setting up the content framework, each game was assigned a unique character to help with the development of EI. Each game had four important features to focus the attention of the DHH learners. The storyboard began by defining a name linked to the game. This was found in the first scene of each game. The next page explained how to play the game. A game summary was presented with videos available from the translator. Next, the main content of each game was introduced. The main content varied in order to develop EI in the DHH learners while the final scene of the game summarized the game concept. For example, the game in Figure 2 focuses on developing EI for competence related to self-motivation, problem-solving, and interpersonal relationships.

In this scenario presented in Figure 2, focusing on problem solving, on Friday evening the students' parents would bring them home. However, on this evening, their parents 
could not bring them home. The students were provided with 50 baht each to return home by themselves. Thus, they had to plan the route home under this constraint. The game requires them to solve the problem: In what kind of vehicle would they be able to return home with this amount of money?

$$
\text { GAME FOR DHH }
$$

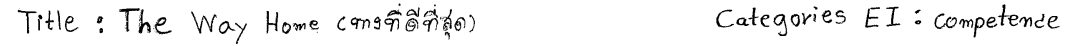

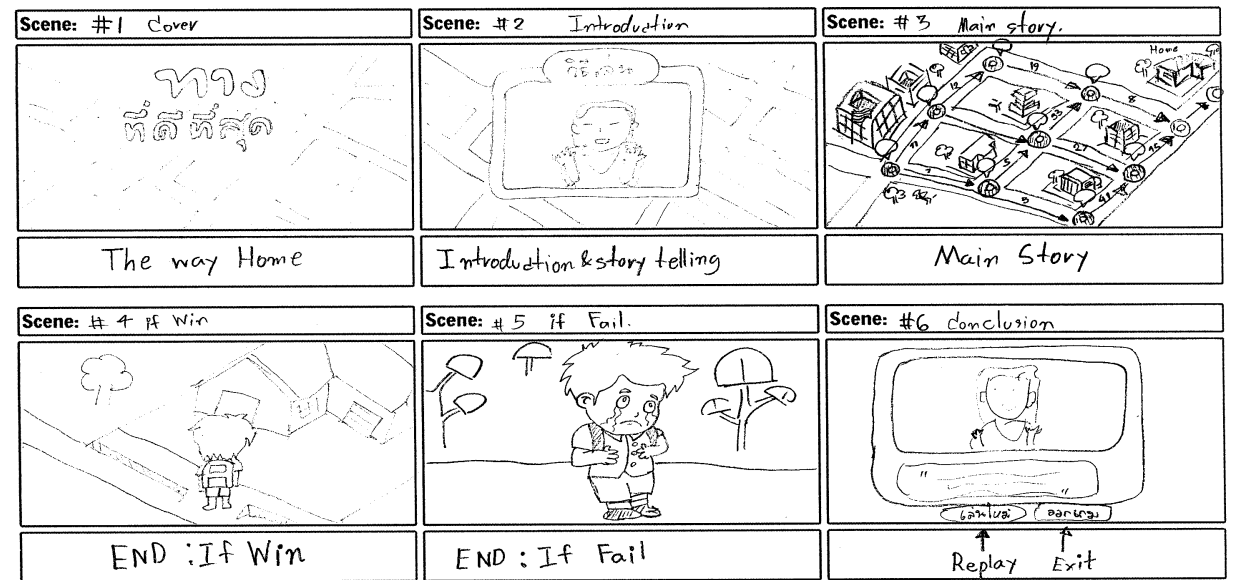

Figure 2

Storyboard "The Way Home"

Step 3: Verification of content and storyboard by five experts

Once the storyboard was created, five experts were invited to determine whether the content was relevant or not to the development of EI for DHH. The experts were in the fields of computer technology, special-education pedagogy, impaired hearing, measurement, and psychology. Content validity used the index of item-objective congruence (IOC), which was between 0.67-1.00.

The experts also made recommendations on the quality of the games. For example, the games showed various types of vehicles to select, some of which were unknown to the children, such as the sky train. The experts noted that "the game should clearly give the distance in kilometers to allow the DHH learners to understand" and set the results as "Winners" and "Losers".

\section{Step 4: Create prototype}

In each game, the content was divided into four parts (A-D). Figure 3 shows that " $A$ " is the title page; " $\mathrm{B}$ " is the storytelling and the interpreter describing how to play the game; " $\mathrm{C}$ " is the main content of the game based on the DHH preferences; and "D" is the sign language interpreter's conclusion for the DHH learners to think about. 

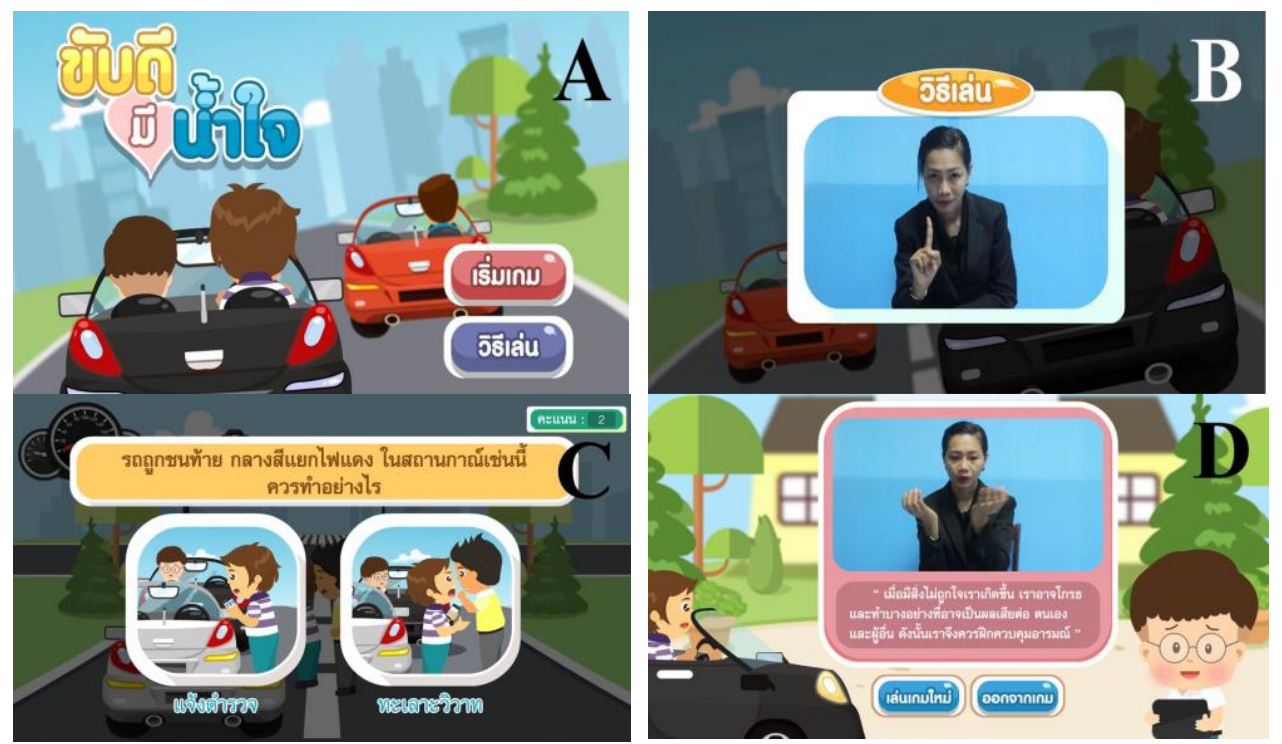

Figure 3

A - Title Page, B - Instructions, C - Main Story and D - Conclusion

Step 5: Testing the prototype

The six games were tested with five DHH learners. The information from this trial was to improve the prototype. The researchers simulated the real experiment situation with the teachers, the sign-language interpreters, and the researcher. The DHH volunteers could stop playing whenever they wanted to. The results revealed that the DHH learners preferred to replay the game several times. Some symbols helped the DHH learners better understand the meaning of the content. For this purpose, the use of pictures or signs instead of textual messages in communication reduced the cognitive load (Mayer \& Moreno, 2003).

\section{Step 6: Redesigning of the prototype}

The games were redesigned so that the DHH learners could play them repeatedly while solving several problems, understanding the solutions rather than memorizing, and not becoming bored in the process. The researchers improved all of the games so that they could be played repeatedly by using the same outline but changing the time sequence of events. For example, in the game in Figure 5, "Crossing the Bridge," five family members have to walk across a bridge in 30 minutes. Each person takes an uneven crossing of the bridge. When the DHH learner starts playing again, the time for each chapter changes and the player must find a way to cross the bridge. This avoids boredom on the part of the players. The players can also play multiple rounds. 


\section{Objectives 2: Assessment, pre- and post-test of the EI of DHH adolescent learners}

\section{Participants}

The participants for objective 2 were 10 DHH learners, four males and six females, aged 13 to 15 . They were provided with a Thai Sign Language (TSL) interpreter to explain the content of the multimedia. The 10 participants' parents or guardians provided consent for them to participate in the games and the students' participation was voluntary. The ethics procedures corresponded to those of the researcher's university and the participating schools approved the study.

The data were collected in a school for the deaf in one of the eastern provinces of Thailand. In this school, they teach children with hearing impairment from grades 1 to 12. Typically, students study computer science for about one hour per week.

\section{Instruments}

The Thai Emotional Intelligence Screening Test (TEIST) developed by the Department of Mental Health (2000) was used as the EI assessment instrument; it was designed specifically for Thai people "due to the belief that Western measures may not accurately measure EI in Thailand" (Sucaromana, 2011, p.17). The test organizes EI into three main categories and nine sub-categories. The TEIST which was developed in Thai, consists of 52 test items on a four-point Likert scale: strongly agree, agree, somewhat disagree, and strongly disagree. Cronbach's alpha value was 0.71-0.88.

\section{Procedures}

The test was administered in the school computer laboratory with the researcher, teacher, and interpreter. There were 12 sessions of 60 minutes each. The main purpose was not to interfere with the DHH learner's normal hours of study. The DHH learners were told the purpose and how to play the multimedia game. The pre-test was followed by a TEIST. This test had no right or wrong answers and the results were not kept in the school record. The participants could stop doing the TEIST any time if they felt uncomfortable. For the second trial, the DHH learner was able to play six games on demand. One computer per player was provided by the school. The $12^{\text {th }}$ session was the post-test of the TEIST. The players could make comments after playing all of the games with the assistance of the sign-language interpreter. The researchers collected the data before the experimental activity. Figure 4 shows the DHH learners participating. 


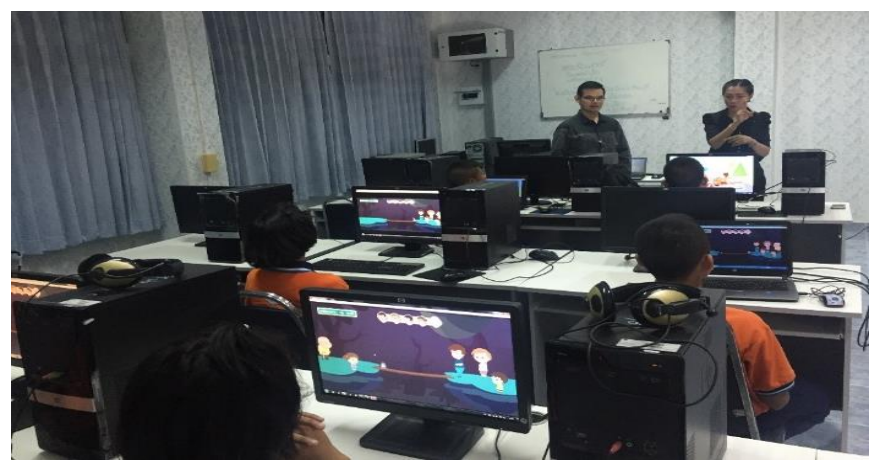

Figure 4

Participating DHH Learners Playing an Interactive Multimedia Game

\section{Data Analysis}

Descriptive statistics were applied for this research. Since the sample was small, the Wilcoxon Signed-Rank test was used to analyse the data.

\section{FINDINGS}

\section{Objective 1: Design interactive multimedia games to meet the needs of learners}

All of the games were created by the researchers, keeping in mind that the content should be developed to focus on virtue, competence and happiness. The titles of the game designs are shown in Table 2, and Figure 5 and 6 show samples of the game design.

Table 2

Games Used in Intervention in Relation to EI Categories

\begin{tabular}{|c|c|c|}
\hline Title & Categories EI & Concept to train \\
\hline Crossing the Bridge & Virtue & Thinking before doing any activity \\
\hline $\begin{array}{l}\text { Good Driving and } \\
\text { Kindness }\end{array}$ & Virtue & Self-control \\
\hline My School & Competence & Understand self-emotion and solve the problem \\
\hline The Way Home & Competence & Ability to solve problems precisely and quickly \\
\hline Knowing Mind & Happiness & $\begin{array}{l}\text { Perceive the emotional state of people from their } \\
\text { facial expression }\end{array}$ \\
\hline Coloring Game & Happiness & Painting with-in the frames for mediation training. \\
\hline
\end{tabular}



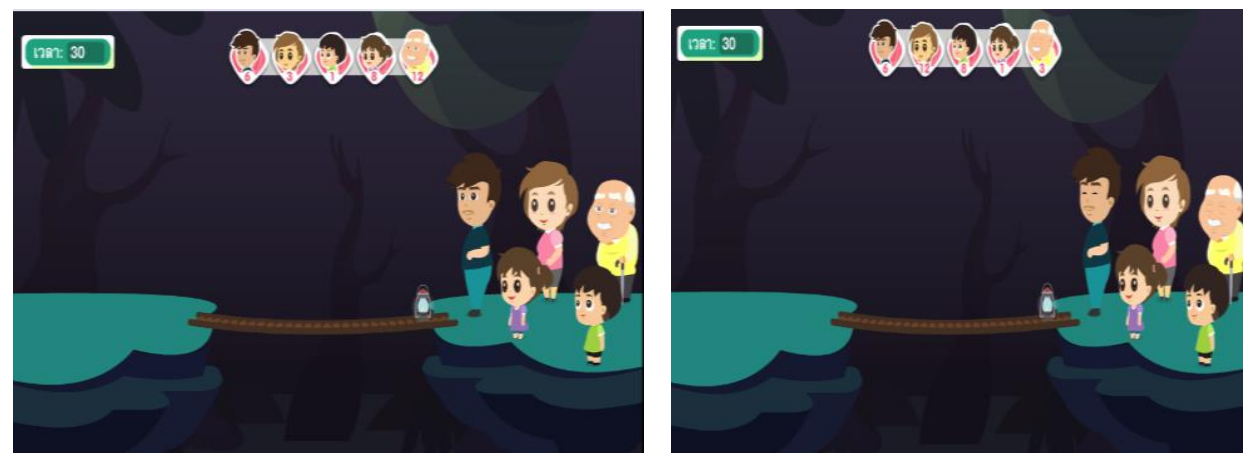

Figure 5

Crossing the Bridge: a Game that Allows Repeated Playing
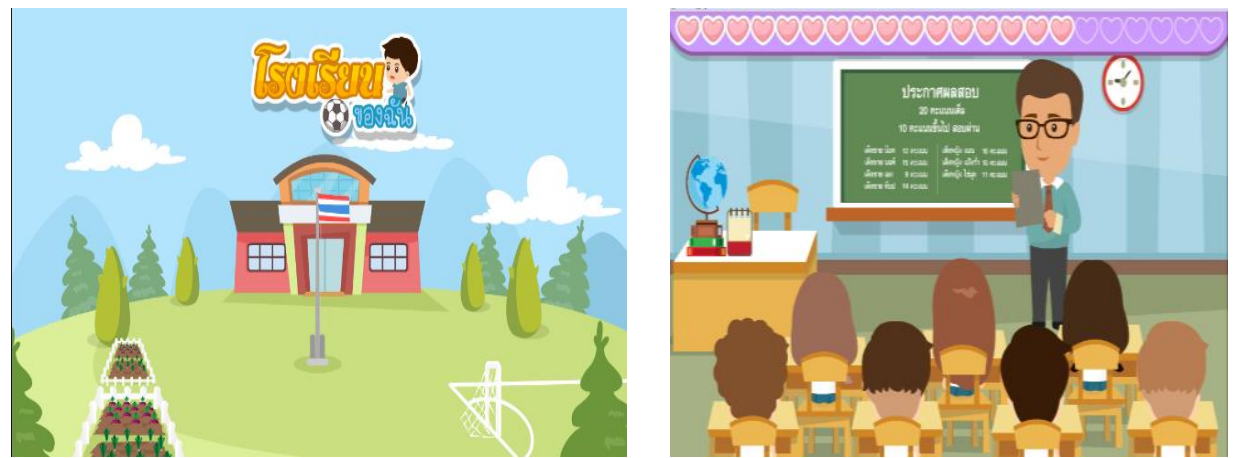

Figure 6

Screen Shot of Title Page and Main Story

Objective 2: Assessment, pre- and post-test of the EI of DHH adolescent learners

The results of the pre and post TEIST are shown in Table 3. Since there was a small number of participants $(\mathrm{N}=10)$, the data were analysed using the Wilcoxon Signed Rank Test. The results showed that the DHH learners achieved significant improvement regarding emotional self-control, empathy, problem-solving, self-regard, lifesatisfaction, and peace. However, the results were not statistically significant for responsibility, self-motivation and interpersonal relationships. 
Table 3

Results of the Pre- and Post- Test $(\mathrm{n}=10)$

\begin{tabular}{|c|c|c|c|c|c|c|}
\hline \multirow[t]{2}{*}{ Categories } & \multirow[t]{2}{*}{ Subcategories } & \multicolumn{2}{|c|}{ Pre-test } & \multicolumn{2}{|c|}{ Post-test } & \multirow{2}{*}{$\begin{array}{l}\text { Wilcoxon Signed } \\
\text { Rank Test }\end{array}$} \\
\hline & & $\hat{x}$ & S.D & $\hat{x}$ & S.D & \\
\hline \multirow[t]{3}{*}{ VIRTUE } & $\begin{array}{l}\text { Emotional } \\
\text { self-control }\end{array}$ & 17.70 & 2.06 & 22.80 & 0.92 & $\begin{array}{l}\mathrm{Z}=2.807 \\
\text { Asymp. Sig }=0.005\end{array}$ \\
\hline & Empathy & 15.90 & 2.33 & 20.60 & 1.65 & $\begin{array}{l}\mathrm{Z}=2.820 \\
\text { Asymp. Sig }=0.005\end{array}$ \\
\hline & Responsibility & 19.10 & 3.14 & 19.60 & 2.59 & $\begin{array}{l}Z=1.633 \\
\text { Asymp. Sig }=0.102\end{array}$ \\
\hline \multirow[t]{3}{*}{ COMPETENCE } & $\begin{array}{l}\text { Self- } \\
\text { motivation }\end{array}$ & 16.90 & 2.47 & 16.90 & 2.47 & $\begin{array}{l}\mathrm{Z}=0.060 \\
\text { Asymp. Sig }=0.952\end{array}$ \\
\hline & $\begin{array}{l}\text { Problem- } \\
\text { solving }\end{array}$ & 14.00 & 2.11 & 19.20 & 2.35 & $\begin{array}{l}\mathrm{Z}=2.844 \\
\text { Asymp. Sig }=0.004\end{array}$ \\
\hline & $\begin{array}{l}\text { Interpersonal } \\
\text { relationships }\end{array}$ & 16.80 & 2.97 & 18.60 & 2.80 & $\begin{array}{l}\mathrm{Z}=1.511 \\
\text { Asymp. Sig=0.131 }\end{array}$ \\
\hline \multirow[t]{3}{*}{ HAPPINESS } & Self-regard & 9.10 & 1.52 & 9.80 & 1.76 & $\begin{array}{l}\mathrm{Z}=2.646 \\
\text { Asymp. Sig }=0.008\end{array}$ \\
\hline & $\begin{array}{l}\text { Life- } \\
\text { satisfaction }\end{array}$ & 17.20 & 3.29 & 19.50 & 2.42 & $\begin{array}{l}\mathrm{Z}=2.555 \\
\text { Asymp. Sig }=0.011\end{array}$ \\
\hline & Peace & 17.20 & 2.82 & 21.60 & 1.26 & $\begin{array}{l}\mathrm{Z}=2.812 \\
\text { Asymp. Sig }=0.005\end{array}$ \\
\hline
\end{tabular}

$* \mathrm{p}<0.05, \mathrm{z}=$ Tested value of the difference between rank.

\section{DISCUSSION}

This study aimed to design and test interactive multimedia games to enhance the social and emotional learning of DHH learners. The study involved identifying the design needs of learners in Thailand, designing games and subsequently testing to see if there were gains in relation to EI. The results revealed significant improvement regarding emotional self-control, empathy, problem-solving, self-regard, life-satisfaction, and peace. Emotional self-control is an EI concept that has been referred to by other researchers (Goleman, 1995). For Sucaromana (2011), emotional self-control refers to "awareness, control and expression of self in a constructive manner" (p. 122). It may also be referred to as impulse control (Sucaromana, 2011). Empathy is also an EI trait identified by other researchers (Bar-on, 1997; Goleman, 1998). For Goleman, empathy refers to the ability to recognize another person's feelings. For Bar-on, empathy is a part of interpersonal ability. For Sucaromana (2011), empathy refers to "awareness, understanding of how others feel, and expression of self in a constructive manner" ( $p$. 121). Problem-solving includes both defining and solving problems by knowing the steps in coming to a solution. Self-regard is respect and confidence in oneself (Sucaromana, 2011) was included in Bar-on's Emotional Quotient Inventory as part of intrapersonal skills. Life satisfaction involves "being optimistic, having a sense of humour and being happy with whatever one has" (p. 121). Finally, peace refers to "having fun, relaxation and having a peaceful mind" (Sucaromana, 2011, p. 121). 
It is interesting to speculate why the games developed these particular attributes versus others. The development of problem-solving ability is to be expected given the association between game-playing and problem-solving (Klopfer \& Yoon, 2005). Gee (2005) noted that games promote problem-solving because users have to set goals and develop strategies in order to win. The games School and the Way Home focused on problem-solving specifically. In the game "The Way Home", the student had a limited amount of money and had to determine strategies to get home from school. There was a time limit in the game as well as a financial limit. Each time the game is played, the route home, options for travel, financial amounts and time limits change so that the student is constantly pushed to solve problems. The games "Good Driving and Kindness" help to develop emotional self-control and empathy. In this game, "Good Driving and Kindness" students are given choices between good and inappropriate behaviours and they are rewarded with points when they choose good behaviours. In terms of competence, the concept of problem-solving is the focus of the game, whereas the attribute of self-motivation is less central.

The attribute of EI requires more time and related experience to develop. Since the activities were designed for use in electronic games on a computer, the program cannot provide interaction with real people. In order to promote the development of the ability to interact with real people, DHH learners must interact with real individuals, not only in the classroom but outside in the community as well (Ibtesam, 2006). Moreover, the proximity between the children as they play the games may assist in improving their interpersonal relationships (Eisenberg et al., 1989). In addition, this multimedia game program may not be suited for promoting responsibility and self-motivation. Motivation requires various components such as blended learning (Wichadee, 2017), which a multimedia game alone does not provide.

Comparisons of results of this study with previous studies are difficult to do because, as noted already, in relation to DHH learners, there have been few efforts to "address the development of educational games for the Deaf" (Khenissi et al., 2015). Barimani, Asadi and Khajevand (2018) studied primary DHH learners as well as hyperactive learners in Iran $(\mathrm{N}=50)$. Twenty of the DHH learners were in the study with ten in a control group and ten in the experimental group. The intervention involved use of nontechnology-based game therapy such as puzzle-making, playing cards. The authors found that "effectiveness of game therapy and emotional intelligence training is higher on social compatibility and communicative skills of hyperactive children than deaf children" (p.7663). Marshall, Carrano and Dannels (2016) used an intervention at the post-secondary level with a control group $(n=34)$ of DHH students, and the intervention group $(n=40)$ DHH students. The intervention involved experiential learning and best practices of STEM instruction to help learners develop problem-solving skills. The intervention resulted in a $14.6 \%$ improvement in problem-solving kills for the control group. These studies' results like those of this study suggest that interventions with DHH learners can improve EI-related aspects in these learners. However, the paucity of studies such as the one presented in this paper suggest that more research is needed. 


\section{CONCLUSION AND IMPLICATIONS}

This study was conducted in only one country, and therefore, it is up to the reader to decide if results may be generalizable to their own context. However, the study does provide new insights into how technology interventions can help DHH learners develop their EI. As the literature review and discussion have shown, there have been few attempts to combine these three areas or EI, and technology with DHH learners.

In terms of implications for the design of games for the DHH learners, the study's results suggest that students can be motivated to play games that involve racing, sports and combat. In contexts where teachers are not able to design actual digital games, faceto-face games can potentially be designed using these themes. Those that are designing digital games for DHH learners should aim to include a video-based explanation with a sign-language interpreter in order to explain how to play the game before participants actually try to play it. The choice of characters should be based on the gender of the player. In this study, the games were designed based on the special needs of the DHH learners. However, teachers and designers can design games based on other frameworks of EI. The study may be replicated in other contexts to determine if the design of the games is relevant for users of different ages than those in this study. Future studies may investigate further the areas which, in this study, did not show gains after the intervention. For example, the DHH learners did not show significant improvement in emotional self-control. Therefore, future studies might look specifically at this particular area to investigate whether there may be more specific requirements in the design for DHH learners to improve this characteristic.

\section{REFERENCES}

Barimani, S., Asadi, J., \& Khajevand, A. (2018). A comparison between the effectiveness of game therapy and emotional intelligence training on social compatibility and communicative skills of exceptional primary school hyperactive and deaf children. International Journal of Pediatrics, 6(5), 7653-7666. doi:10.22038/ijp.2017.27514.237

Barker, L. (2003). Computer-assisted vocabulary acquisition: the CSLU vocabulary tutor in oral-deaf education. Journal of Deaf Studies and Deaf Education, 8(2), 187198. doi:10.1093/deafed/eng00

Bar-On, R. (1997). Bar-On emotional quotient inventory (EQ-i): Technical manual. Toronto, Canada: Multi-Health Systems.

Billings, C., Downey, L., Lomas, J., Lloyd, J., \& Stough, C. (2014). Emotional intelligence and scholastic achievement in pre-adolescent children. Personality and Individual Differences, 65, 14-18. doi:10.1016/j.paid.2014.01.01

Brashear, H. (2007). Improving the efficacy of automated sign language practice tools. ACM SIGACCESS Accessibility and Computing, 89. 11-17. doi: $10.1145 / 1328567.132857$ 
Chebka, R., \& Essalmi, F. (2015). A crosswords game for deaf. 2015 5th International Conference on Information \& Communication Technology and Accessibility (ICTA), 16. doi:10.1109/ICTA.2015.742688

Dammeyer, J. (2010). Psychosocial development in a Danish population of children with cochlear implants and deaf and hard-of-hearing children. Journal of Deaf Studies and Deaf Education, 15, 50-58.

Department of Mental Health. (2000). The development of Thai emotional intelligence screening test for ages 12-60. Thailand: Department of Mental Health.

Donne, V. \& Rugg. N. (2015). Online reading practices of students who are deaf/hard of hearing. Deafness \& Education International. 17(3), 144-154. doi: 10.1179/1557069X15Y.0000000001

Eisenberg, N., et al. (1989). Relation of sympathy and personal distress to prosocial behavior: A multimethod study. Journal of Personality and Social Psychology, 57(1), 55-66. doi:10.1037/0022-3514.57.1.55

Gee, J. P. (2005). Good video games and good learning. Phi Kappa Phi Forum, 85, 33 37.

Giannakos, M. N., \& Jaccheri, L. (2014). Code your own game: the case of children with hearing impairments. International Conference Entertainment Computing, 108-116. Sydney: Springer. doi:10.1007/978-3-662-45212-.

Ghoul, O. E., \& Jemni, M. (2009). A sign language screen reader for deaf. 5th Symposium of the Workgroup Human-Computer Interaction and Usability Engineering of the Austrian Computer Society on HCI and Usability for e-Inclusion, 476-483. doi:10.1007/978-3-642-10308-7_3

Goleman, D. (1998) .Working with emotional intelligence. New York, NY: Bantam Book.

Goleman, D. (1995). Emotional intelligence. New York, NY: Basic Books.

Hansenne, M. \& Legrand, J. (2012). Creativity, emotional intelligence, and school performance in children. International Journal of Educational Research, 53, 264-268. doi:10.1016/j.ijer.2012.03.01

Holmer, E., Heimann, M., \& Rudner, M. (2017). Computerized sign language-based literacy training for deaf and hard-of-hearing children. The Journal of Deaf Studies and Deaf Education, 22(4), 404-421. doi:10.1093/deafed/enx023

Ibrahim, Z., Alias, N., \& Nordin, A. B. (2016). Needs analysis for graphic design learning module based on technology \& learning styles of deaf students. Cogent Education, 3(1), 1-14. doi:10.1080/2331186X.2016.1178364

Ibtesam, H. (2006). The impact of student faculty informal interpersonal relationship on intellectual and personal development. Abu Dhabi: College Student Journal, 40. 
Keilmann, A., Limberger, A., \& Mann, W. J. (2007). Psychological and physical wellbeing in hearing-impaired children. International Journal of Pediatric Otorhinolaryngology, 71, 1747-1752.

Khenissi, M. A., Bouzid, Y., Essalmi, F., \& Jemni, M. (2015). A learning game for deaf learners. 2015 IEEE 15th International Conference on Advanced Learning Technologies, 418-422. doi:10.1109/ICALT.2015.98

Klopfer, E., \& Yoon, S. (2005). Developing games and simulations for today and tomorrow's tech Savvy Youth. Tech trends. Linking Research \& Practice to Improve Learning, 49(3), 33-41.

Lee, S., et al. (2005). A gesture-based American Sign Language game for deaf children. Extended Abstracts on Human Factors in Computing Systems, 1589-1592. doi: $10.1145 / 1056808.1056973$

Marshall, M., Carrano, A., \& Dannels, W. (2016). Adapting experiential learning to develop problem-solving skills in deaf and hard-of-hearing engineering students. The Journal of Deaf Studies and Deaf Education, 21(4), 403-415. doi:10.1093/deafed/enw050

Mascio, T. D., Gennari, R., Melonio, A., \& Vittorini, P. (2013). Designing games for deaf children: First guidelines. International Journal of Technology Enhanced Learning, 5(3/4), 223-239. doi:10.1504/ijtel.2013.059493

Masoume, P. T., Mohammad, A., \& Seyede, S. J. (2013). The effectiveness of emotional intelligence training on the mental health of male deaf students. Iranian Jounral of Public Health, 42(10), 1174-1180.

Mavroveli, S., Petrides, K., Shove, C., \& Whitehead, A. (2008). Investigation of the construct of trait emotional intelligence in children. European Child \& Adolescent Psychiatry, 17, 516-526. doi:10.1007/s00787-008-0696-6

Mayer, R., \& Moreno, R. (2003). Nine ways to reduce cognitive load in multimedia learning. Educational Psychologist, 38, 43-52.

Mayer, J. D., \& Salovey, P. (1995). Emotional intelligence and the construction and regulation of feelings. Applied \& Preventive Psychology, 4, 197-208. doi: $10.1016 / \mathrm{S} 09621849(05) 800587$

Nicoletta, V., \& Ronnie, W. (2007). Novel approaches to deaf education. First International Conference on Technology Based Learning with Disability, 22-25.

Passig, D., \& Eden, S. (2000). Enhancing the induction skill of deaf and hard-of-hearing children with virtual reality technology. Journal of Deaf Studies and Deaf Education, 5(3). 277-85. doi:10.1093/deafed/5.3.277

Perry, D. G., Hodges, E. V. E., \& Egan, S. K. (2001). Peer harassment in school: The plight of the vulnerable and victimized, 73-104. New York, NY: Guilford Press. 
Petrides, K. V., Fredericksonb, N., \& Furnham, A. (2004). The role of trait emotional intelligence in academic performance and deviant behaviour in school. Personality and Individual Differences, 36, 277-293.

Rafaila, E. (2015). Primary school children's emotional intelligence. Social and Behavioral Sciences, 203, 163-167. doi:10.1016/j.sbspro.2015.08.276

Rieffe, C., (2012). Awareness and regulation of emotions in deaf children. British Journal of Developmental Psychology, 30(4), 477-492. doi:10.1111/j.2044835X.2011.02057.x

Salovey, P., \& Mayer, J. D. (1990). Emotional intelligence. Imagination Cognition and Personality, 9(3), 185-211. doi:10.2190/dugg-p24e-52wk-6cdg

Sucaromana, U. (2011). The Thai emotional intelligence screening test: measurement and validation with pre-service teachers (Unpublished doctoral dissertation). Griffith University, Logan.

Techaraungrong, P., Suksakulchai, S., Kaewprapan, W., \& Murphy, E. (2015). The design and testing of multimedia for teaching arithmetic to deaf learners. Education and Information Technologies, 22(1), 215-237. doi:10.1007/s10639-015-9441-1

Tresh, J. (2004). In the face of force: Helping deaf children cope. New Directions in Deaf Education, 5(2), 34-36.

Visutsak, P. (2016). The repertory grid method for Game-Based learning approach: A case study in stem. 9th Annual International Conference of Education, Research and Innovation, 2251-2257. Seville: Spain.

Wichadee, S. (2017). A development of the blended learning model using edmodo for maximizing students' oral proficiency and motivation. International Journal of Emerging Technologies in Learning, 12(2), 137-154. doi:10.3991/ijet.v12i02.6324 